\title{
Effective Boards of Directors: A New Approach
}

\author{
Igor Belikov \\ Director \\ $\underline{\text { ORCID }}$ \\ E-mail: igor_rid004@list.ru \\ Russian Institute of Directors, Moscow, Russia
}

Journal of Corporate Finance Research, Vol. 13, No. 1, pp. 120-130 (2019)

DOI: https://doi.org/10.17323/j.jcfr.2073-0438.13.1.2019.120-130

Received 15 October 2018 | Peer-reviewed 12 December 2018 | Accepted 5 March 2019 


\section{Effective Boards of Directors: A New Approach}

\section{Abstract}

The goal of this study is essentially twofold. First, it seeks to improve the efficiency of management in Russian companies through a revitalisation of perspectives on the makeup and activity of boards of directors. Second, it seeks to develop a motivation among controlling shareholders to strengthen the actual role of such boards in managing companies. This combined approach is intended to be applicable to both public and private companies.

The objective of this study is to search for ways to refocus on standard recommendations for international best practice regarding the work of boards of directors. These recommendations should consider best practices in terms of general company control and supervision, the in-depth study of key business processes, management innovations, technologies, and tools to promote new management approaches. A feature of this investigation will be the identification of ideas to ensure the best paths towards overcoming psychological barriers that impede the adoption of innovative and novel ideas by management.

This article provides a comparative analysis of the classic Anglo-US model of corporate governance (which features the role of boards of directors as the body exercising control and supervision over the company's activities and its management), with the Russian model. The Russian model is characterised by a structure which nominally replicates the practice of developed countries, whereby the real power rests with the controlling shareholders and management, with the boards playing a secondary role by approving the plans of the company activities and their results.

Given this situation, the boards of directors of Russian companies should prove their capability to contribute to the creation of economic value. Examples of essential management areas in which boards of directors should implement the function of management development are: strategic planning, creating and improving competitiveness, building up and developing the company's human capital, risk management, and internal control. This article suggests efficient practices and tools which can be used by a board of directors for management development.

Keywords: board of directors, controlling shareholders, management, business council, experience economy, company's risk culture

JEL-classification: G32, G34, M14 


\section{Introduction}

In the present-day context, business process management has globalised. The format and processes relating to official company documentation which stipulate the functions of management bodies, and the legal norms governing such activities, have become increasingly unified. However, notwithstanding their formal resemblance, the actual work of management bodies of companies often varies greatly on an international level. Thus, the role of a board of directors in managing a public company varies in developed and developing countries. The model of the board, as a body monitoring and supervising the activities of the company and its management (as adopted from the practice of countries with developed markets), is fully duplicated in Russia from a legal viewpoint. However, in practice, the boards of directors play a much more modest role in the governance process in the vast majority of the Russian public companies. In actuality, real power rests with the controlling shareholders and management (which are often the same people), while the boards play a mostly secondary role, considering and officially approving the plans of the company activities and the results of their implementation. Such a situation is peculiar to most countries with emerging markets. However, in this article we will focus on the situation in Russia.

The discrepancy between the official powers of the governance bodies and their actual activities always creates serious risks and reduces management efficiency. Although, in order to eliminate or at least mitigate this gap, it is necessary to understand the causes of this discrepan$c y$, and the causes of its persistence.

It may be fairly stated that a misunderstanding of these causes gives rise to the wrong methods for addressing them, and often serves only to exacerbate the problem.

\section{Boards of directors:}

\section{Principles of the classical model}

In the Anglo-US model of corporate governance that dominates throughout the world, the right of the board of directors to exercise strategic management and control arises out of the ownership structure of public companies. Western public companies tend to have a dispersed ownership structure. Most of these companies do not have a controlling shareholder, and very often do not even have a significant major shareholder (e.g. a shareholder owning more than $10 \%$ of shares, or even $5 \%$ ). The volume of stock owned by managers is also rather small.

It is not surprising then, that in such a situation the board of directors is considered the appropriate body to represent the interests of all shareholders, and therefore has the right to control management, approve critical decisions, evaluate work, determine management remuneration, and decide on management replacement if the company shows unsatisfactory performance [1].

The dispersed structure of the share capital in such companies determines the mechanism for electing members of the boards of directors: it is arranged in such a way as to prevent the board's dependence on any one group of shareholders.

A large community of top managers from these countries is constantly replenished by people from all over the world, and thus results in a strongly competitive environment. This community may be described as possessing a very professional culture, based on the existing business infrastructure and the traditional modes of professional communication. In this respect, respected professional periodicals on management and corporate governance, affluent professional associations, management research centers, conferences, and leading world business schools all form foundational touchstones for the culture of professionalism [2]. The high level of competency within this community is confirmed by the large number of companies, which are among global industry leaders, innovative companies, and companies with original management models. The boards of directors of western companies have a wide range of choice of candidates to replace top executives who show performance results that do not satisfy shareholders.

Additionally, the high liquidity of the stock market allows shareholders to easily withdraw their interests in companies when poor or with unsatisfactory performances. The effective judiciary systems of these countries also makes it possible to take independent decisions regarding shareholder disputes, and to bring the management and members of the boards of directors to justice if abuses in the performance of their duties takes place.

Under these circumstances, the main function of boards of directors is general supervision and control over the activities of management [3]. The logic of this approach is that in the event of poor company performance, the board of directors should replace management, and not be dragged into problem-solving processes. Although in recent years the general trend has been an increase in the time spent by members of the boards of directors of Western companies on fulfilling their duties, their excessive activity is viewed cautiously as a risk factor regarding interference with the scope of appropriate management responsibility.

\section{Boards of directors in Russia: The different model}

The ownership structures in public Russian companies and the environments in which they operate are very different from their counterparts in Western countries.

All Russian public companies are characterised by a very high ownership concentration, with the power invested in an controlling shareholder (or a small group of shareholders) to determine the composition of the board of directors. Hence, there is often the possibility of a change in board composition at any time. The controlling shareholders of Russian companies are deeply involved in the management process, to the extent of direct participation in operational decision-making. They closely interact with the management of companies and commonly establish informal relationship with them, which is facilitated by the extremely controversial nature of legal regulation. An essential characteristic of the environment in which Rus- 
sian companies and their major shareholders operate is the low level of trust in society as a whole, and in the business environment [4]. The Russian judicial system is ineffective in ensuring the just resolution of shareholder conflicts, countering corporate raiding, and recovering damages from management and board members in cases of abuse. It is not surprising then, that under conditions of a high concentration of ownership of public Russian companies, their major shareholders believe that, from an economic perspective, the right to exercise effective control over the activities of a company is vested in them, and not in the boards of directors. In the minds of major shareholders, the nominal legal right of boards to exercise supervision and control has no basis in terms of the nature of ownership relations in these companies. Given the state of the general business environment, Russian majority shareholders view the transfer of the actual functions of control and supervision over the activities of their companies to boards of directors as a significant risk [4]. As a result, the practice of most boards of directors is perfunctory, and the range of tools and technologies they use is very limited. Board members, as a rule, understand these limitations and their reasons, which has implications for their levels of activity.

Mastering the basics of western best practice in corporate governance, the principles of establishing and organising the work of boards of directors by a growing number of large Russian companies from the late 1990s to the late 2000s relied on the interest of their controlling shareholders in increasing the market capitalisation of their companies. However, even during this period, such a factor did not lead to the transformation of boards of directors into bodies that exercise effective control over companies. One of the reasons for this is the short-term orientation of most foreign portfolio investors in the Russian stock market, and the determining influence on their behavior of macroeconomic, and political factors alongside trends in commodity prices. Furthermore, under the conditions of the overall high attractiveness of emerging markets (and the rapid growth of the Russian economy), mastering even a limited set of elements of organising the work of boards of directors under the Anglo-US model (election of several independent directors, establishment of board committees, adoption of a number of internal documents) yielded positive results in the form of rapid capitalisation growth [3].

However, since the late 2000s the prospect of growth in market capitalisation has almost lost its importance in the minds of Russian shareholders as a factor for stimulating an increase in the role of boards of directors. This is due the following reasons:

- a stagnation of the Russian economy, reducing its attractiveness for Western investors;

- a decrease in demand for investments from Russian companies themselves;

- a drastic reduction in opportunities for capitalisation growth due to exodus of Western portfolio investors;

- domestic political restrictions on the transfer of control over large Russian companies to foreign investors.
In the view of the author, in the foreseeable future, there is no reason to expect that the interest of Russian controlling shareholders in growing the capitalisation of their companies will be a driver for the transfer of actual supervisory powers to boards of directors. There is also no reason to expect a qualitative decrease in the ownership concentration in Russian companies. In a great number of the largest Russian companies partially owned by the government, the practice of forming strong personal relations between top management and representatives of top political leadership [4] contributes to preserving the current nominal role of boards of directors.

Since 2000s, a significant factor contributing to the adoption of Western corporate governance practices by large Russian companies has been the activity of the stock market regulatory authorities - first of the FCSM-FFMS, and then of the Central Bank of the Russian Federation. In recent years, in the author's estimation, this factor has become the most crucial one. However, the persistence of high ownership concentration in Russian public companies alongside a notable decrease in any economic interest from shareholders in the transfer of power to their boards of directors should lead to a growing concern about the impact of the regulatory factor. Increased pressure from the regulator on non-state-owned companies to try and force controlling shareholders to transfer actual control to the boards poses a risk of increased simulation of the work of boards in key areas of their responsibility.

\section{Professional management development as a key function of the board of directors}

In the current situation, in order to significantly increase their involvement in strategic management, the boards of directors of Russian companies need to prove to controlling shareholders they have the capability to contribute to the creation of economic value. The boards could do this through a vigorous development of professional company management in areas which form long-term competitive advantages, and by focusing on unconventional approaches to understanding and solving relevant challenges. To this end, board members should master and actively use new, effective practices, technologies, and tools for analysing management issues and researching their solutions. In the author's view, the most important areas of management in which the boards of directors of Russian companies should implement this function are as follows: strategic planning, ensuring and improving competitiveness, building up and developing the company's human capital, risk management, and internal control. The implementation by boards of directors of these functions can demonstrate their value to controlling shareholders, giving the latter serious reasons for delegating effective powers to boards and bestowing upon them a real influence in the management process [5]. It could also lay the foundations for meaningful collaboration between the boards and management as a joint team of the company. Within such a proposed professional development initiative, the interaction of controlling shareholders, manage- 
ment, and board members would ideally be carried out on a basis that assuages any possible psychological challenges for shareholders.

What could induce the controlling shareholders of Russian companies, at least in part, to move away from their current sole reliance on management as the only source of value creation and development drivers? In the opinion of the author, the increasingly evident inefficiency of the present model, and its increasing non-competitiveness, is just such a factor.

With the high level of top managers' remuneration in large Russian companies (which has reached, and in a good number of cases, exceeded the level of remuneration of company leaders in countries with developed markets), Russian companies increasingly lag behind companies of developed countries and a growing number of companies from emerging markets in key areas [6].

Here are some stark examples that characterise the low quality of management in Russian companies (according to 2015-2016 research data): the share of companies with network management and flexible corporate systems in the world totally is $61 \%$, while in Russia this figure lies at $36 \%$; levels for leadership training programs with strategic goals in the world totals $61 \%$, whereas in Russia this figure is $36 \%$; the level of coverage by managerial development training programs for lower and mid-level managers in the world is $42 \%$, yet in Russia is just $18 \%$; Russia ranks last in a selection of 28 countries in terms of staff readiness to interact with colleagues within cross-functional teams; and finally, $80 \%$ of Russian companies do not carry out any analytics in the field of human resource management. In the ranking of the most technologically advanced companies in the world as of the end of 2016, Russia is represented by one company (Magnit), the same number as Saudi Arabia and Chile. In the ranking of the 50 most innovative companies in the world as of the end of 2015, compiled by Fast Company, there are no Russian companies, but companies from Malawi, Chile, and several companies from China and India are represented. In the ranking of the 50 most innovative companies in the world as of the end of 2015, made by the Boston Consulting Group, there is no Russian company. In terms of the labour productivity index in 2013 (in US dollars in 2013 prices adjusted for PPP), according to the Conference Board and Eurostat, Russia ranked 42nd, lower than not just all European countries, but also Turkey, Trinidad and Tobago. According to the OECD, ranked by the share of GDP per 1 hour of work, at current prices, as of the end of 2015, Russia ranks 36th, which is lower than Turkey and Chile and slightly higher than Mexico, (a drop from the 2014 position). For the period 1991-2012 Russia has increased labour productivity by about $30 \%$, while China has done so by $700 \%$. According to estimates by experts, labor productivity in Russia is 4 to 10 times lower than the corresponding indicator of developed countries. It is fair to say that a very large share of responsibility for such "achievements" rests within the business environment.

Business processes all over the world are increasingly determined by factors that pose even more serious challenges to the current practices in Russian company management and governance. These include a dramatic increase in the value of human capital and collective experience, the significance of considering the psychological aspects of management processes, openness to information from external sources, the ability to encourage unusual views and ideas, and the importance of professional reflection [5].

The ability to draw the attention of controlling shareholders to these factors, to effectively help the formation of relevant qualities among top managers, is a chance for the boards of directors of our companies to become a really significant component of management processes.

In the author's view, the idea of increasing the contribution of the board of directors to the development of large companies through the implementation of the "Business Council" model is unpromising. This term refers to a practice whereby the board members themselves propose specific business ideas and projects, effectively influences their implementation, and features their involvement in the project management processes [2]. Such a model of the board of directors is common in startups and companies at an early stage ("infancy" stage according to I. Adizes). However, at the advanced stages of a company's life cycle, interference with the competence of management (e.g. the actual substitution of its functions in any scope) leads to a dilution of responsibility for the overall performance of the company, and gives rise to conflicts of interest. The development of professional management in the company also requires a professional board of directors. The contribution of the board of directors of a large Russian company to the creation of economic value should be primarily the function of the professional development of management with the gradual expansion of effective supervision and control [7].

As previously asserted, the author stresses that the following are the most important areas to implement professional development of management for Russian companies by the boards: strategic planning, creation and improvement of competitiveness; building-up and development of the company's human capital; risk management and internal control.

\section{Role of the board of directors in professional development in key management areas}

\section{Strategic planning, creation and improvement of competitiveness}

In accordance with the provisions of applicable corporate law, and the recommendations of the Bank of Russia Corporate Governance Code (based on the classical model of the board of directors formed in countries with developed markets), board members should focus on the analysis of strategy validity at the stage of its discussion. They should also focus on the analysis of performance against the stated objectives and specified indicators, and finally, they should focus on the correspondence of ongoing and proposed new projects under approved strategies [8]. These discussions in Russian boards are often of a technical 
nature. The attention is focused on simply specific details (a set of benchmarks, target values, causes of deviations from target results, arguments for adjusting targets, etc.). Meanwhile, the overall logic of the strategy and management actions are not considered for analysis.

Within the developmental process of management in the fields of strategy and competitiveness, members of the board should aim to build management's ability to take a fresh view of the company's business and the environment in which it operates [9]. As A. de Geus, the former head of the strategic planning for Shell, noted, "planning exists not to make plans, but to change ideas".

A set of possible approaches and topics that will help the management to form a systematic and novel view of the company's business and its environment may vary. It is generally determined by the professional experience and knowledge of the board members.

In this author's opinion, it is useful for members of the board to focus their attention on the aspects outlined below.

\section{The company's business model as an integral indicator of performance, competitive advantage and sustainability}

Consider a company's activities in the example of a working business model that links production and technical solutions with the right economic results. Members of the board and management of such a company can jointly formulate answers to the following questions: what is the company's specific business model with reference to the current strategy? To what extent is a differentiated access to key resources required for the current business model? How well are intra-company processes developed within the business model which are aimed at creating value for the consumer, but are difficult to replicate for competitors? To what extent does the existing system of remuneration of management and employees correspond to the current business model? Which trends in this business environment are of particular importance for the company? Do these trends enhance or minimise the disadvantages and advantages of our company's business model?

\section{The ability of management to organise a process for developing their own innovations, but also for replicating ("imitating") innovations borrowed from outside}

Avant-garde theorists and business practitioners have already overcome the idea that borrowing innovation as something improper and not worthy of interest. Let us cite O. Shenkar, the head of Ford Motor Company's board for global business management: "Imitation is a strategy which is not only consistent with innovation, but is necessary for concentrating and effectively using innovative capacities... A systematic, consistent approach to imitation is needed as part of the company's strategy". The term "innovative companies" has long been established, referring to those companies that successfully and cost-effectively integrate replicated elements ("imitations") with ingenuity and knowledge of context, as well as a broad approach to selecting objects for replication. These objects can be a product, process, procedure, or business model. Research into sharing benefits from the introduction of innovations in the American economy for 1948-2001 showed that innovative companies received only $2.2 \%$ of the present value of their innovations.

As part of the discussion of this area of activities, members of the board and management can jointly formulate answers to the following questions: Does the company have a policy of targeted analysis and selection from outside of new products, services, procedures, processes, models and ideas? To what extent is such a policy consistent with the company's strategy and the business model it uses? What is being done in the company for the formation of a culture and attitudes that not only accept, but also value and promote borrowing and imitation as well as their own innovations? Where did new ideas for the industry and the company come from over the last five years that led to the creation of new products, services, procedures, processes, and models? How do the principles of motivation of personnel promote the policy of borrowing and developing new products, services, procedures, processes, models and ideas?

\section{The effects on the company's business of global trends in the use of "big data" and information and internet technologies}

Within the opportunities created by the development of information technology and the internet, we can outline at least three areas for discussion in the company:

- the use of "Big Data" to obtain new knowledge about the state of the markets, industries and customers of interest to the company;

- the application of information technologies for the integration of business processes, the creation of new products/services and new ways of delivery, end-to-end processes from ordering, designing, and manufacturing to sales and servicing, and the formation of business ecosystems;

- the use of information technology to personalise customer relationship.

In discussing the potential opportunities created for the company's business within both the above and other areas related to the use of information and internet technologies, members of the board of directors and management can jointly formulate answers to the following questions: What economic value for the company can be created by centralised accumulation, storage, and processing of data about the company's business (its internal and external sides), and by mastering the technology of "Big Data"? What are the dynamics of the use in the industry of information technology to integrate business processes and companies' businesses, the creation of new products/ services and delivery methods, end-to-end processes from ordering, designing and manufacturing to sales and servicing, and building business ecosystems? How does management see the economic value of using this experience in our company? What economic value can a company create by personalising relationships with its customers? Which examples of personalisation of relations with cus- 
tomers in our industry or related ones exist abroad? What technical and organisational capabilities does the company have for this approach to customers?

\section{Feasibility and capabilities of the company to offer experiences as a new kind of economic proposal ("experience economy")}

Increasing competition encourages companies to seek new ways to form their uniqueness [10]. One of the features of this tendency is the determination of the economic offer to consumers, in which the stable emotional experience of the customer when interacting with the company constitutes a key or very significant component. The basis for the growing attention of companies in various industries to this area is the new technological capability to create strong positive experiences for consumers through mass personalisation of a companies' offers at competitive (sometimes tailored) prices.

From the perspective of "experience economy" principles, members of the board and management can jointly formulate answers to the following questions: What economic value for the company can be created by using the concept of "experience economy" in relations with its customers? What technical and organisational capabilities does the company have for this approach to customers? Which elements of Russian and international experience in customer relations can be applied in our company?

\section{Creation and development of the company's human capital}

The quality of human capital is increasingly viewed throughout the world as the main competitive advantage of companies. The assistance of the board of directors to the professional development of management in matters of strategic development and competitiveness is in itself a contribution to the development of the company's human capital (at the level of top management) [11]. But this is not enough. Further targeted work of a board is needed to promote the development of the company's human capital on a wider scale.

As concerns the professional development of management in the field of creation and development of the company's human capital, members of the board should focus their attention on the below aspects.

\section{Search for new organisational structures that promote self-organisation and the creative potential of employees}

A growing number of companies realise that the behavior of employees in the workplace is largely determined not by training, but by the organisational structures of the company within which they have to operate. The response to this understanding is the expanding practice of experimentation with organisational structures with a view to seeking a good balance over several variables, including: reliability, willingness to perform standard actions, flexibility, independent responses to non-standard work related issues, the company's various subdivisions, and the taking of proactive steps to reduce business and strategic risks [12].

As part of the discussion of management practices to promote business-conscious behaviour, board members and management can jointly seek answers to the following questions: How should the balance of business process reliability and flexibility change within the framework of the current development strategy of the company? Which business processes need organisational behaviour among employees based on flexibility and adaptability? What measures does management implement to develop organisational behaviour among employees based on flexibility and adaptability? What are the results of these measures? What steps to change the organisational behaviour of employees are taken by industry leaders, and the company's main competitors in Russia? Which useful lessons can be learnt from them for our company?

\section{Principles of the company's management team building}

In the managerial practice of world leading companies, the formation of top management based on the principles of a 'complementary team' is gaining recognition [13]. Each member of such a team assumes the role and functions necessary for the effective work of the executive body, which are inextricably linked with different types of personality among the members of the management team. The classification of types of managers, developed by I. Adizes, can serve as an example. A particular strength of the first of these types of personalities is the organisation of the company's work to achieve current operational objectives; of the second - the systematisation of management processes; the third one is characterised by longterm vision, the ability to offer fresh ideas, and a willingness to accept risks in achieving large-scale results in the future; the fourth reflects the creation of an environment and a system of values that will encourage people to act jointly. The non-availability of a representative of one of these types of managers in the management team greatly reduces the overall effectiveness of its work.

Board members and management can jointly formulate answers to the following questions: What does the optimal composition of our company's management mean in terms of complementary managerial roles? How does management take into consideration the principles of forming a complementary team in the process of searching for candidates for key managerial positions in a company? What is the practice of personal involvement of top managers in the selection and professional development of key management personnel of the company, taking into account the principles of team building?

\section{Qualitative improvement of the company's HR service practice}

Leading global companies are actively seeking ways to enhance the integration of their HR units in the management process, and increase their contribution to the creation of economic value. For example, a company might assigning their HR team certain new tasks, such as the evaluation of the staffing of the company's strategy and diagnosing problems in this area. They might challenge them with forecasting team performance, or the development of proposals to improve the company's competitiveness in terms of its human capital (organisational behavior, qualification, motivation, etc.). HR units may formulate a task aimed at the composition of key perfor- 
mance indicators, or at participation in budgeting. Board members and management can focus their attention on regular discussion of these issues and jointly search for answers to the following questions: What economic value for the company does the work of HR units create, and how is it measured? In which areas should the HR units make the greatest contribution to achieve the company's strategic goals within the approved strategy? To what extent is the performance assessment, and the motivation principles of the HR team vis-a-vis business objectives, approved as part of company strategy? To what extent is the head of the HR units involved in the most important management decisions of the company? Does management find this involvement to be optimal?

\section{Improved management of internal company knowledge}

The systematisation of knowledge and skills of employees, and the motivation of employees to expand this knowledge base and its mastering are a recognised part of management practice not only in the leading companies of developed countries, but also of a growing number of companies from emerging-market countries [13]. This practice makes it possible to identify, formalise, and disseminate practical solutions that provide the greatest economic effect within the company. This can also help to reduce losses in the event that such knowledge holders leave the company, and evaluate the practical impact of external employee training [11]. In analysing the company's practice in this area, board members and management can jointly formulate answers to the following questions: what are the main components of the company's internal corporate knowledge management practice? What economic value does this company system provide? How does the cost of external and internal training of personnel contribute to the growth of internal corporate knowledge? How is the development and use of this system incorporated in the current system of personnel motivation at various levels?

\section{Personnel performance assessment practice}

A growing number of companies in countries with developed and emerging markets are seeking a balance between the traditional annual assessment and intermediate performance assessments of employees. This goal is sought after in order to more promptly adjust workloads, and to identify ways of effectively combining formal assessment and managers' experienced judgment on the performance of a subordinate. The assessment focus often shifts towards future goals and development potential, and various software applications are being actively implemented which enable a quick analysis of the results of interim assessments to promote best practice in internal corporate communications [12]. In discussing these issues and studying best practices, members of the board and management can jointly develop answers to the following questions: To what extent is the company's employee assessment system optimal in terms of combining operational and strategic objectives? To what extent is the relationship between the criteria and the results of assessment of employees of different motivational levels optimal? To what extent is the development and implementation of effective ways of employee assessment incorporated in the principles of performance assessment and motivation of the HR service and its manager?

\section{The work of the board on risk management, and the creation and development of the internal control system}

The critical importance of attention to risk management is determined by such trends as a sharp increase in uncertainty about the future at global, regional, country, industry and corporate levels; increased non-linearity of industry development; and rapid technological changes that can drastically disrupt industries or business models, and destroy boundaries between industries [10].

Within the function of professional development of management in the field of risk management and internal control, it is useful for members of the board to focus their attention on the below aspects.

\section{General principles in the formation of risk management and internal control system}

The approach to the establishment of an integrated risk management system by incorporating risk management into all business processes in a company has become a widely recognised approach. Companies strive to form a balanced risk profile through the right combination of high and low risk activities, and the correct use of asymmetry and non-linear effects. Risk is considered not only as a threat, but also as an opportunity. Instead of efforts to improve the accuracy of forecasting negative probabilities, companies focus on increasing the flexibility and adaptability ("antifragility") of the company's internal processes to possible negative events [14]. In discussing these issues and studying best practices, board members and management can jointly develop answers to the following questions: What is the extent of adaptability and flexibility of the company's internal processes to changes? What plans are in place to increase it? Does the current strategy of the company contain a strong negative asymmetry, by considering the likelihood of large losses in the event of changes in the basic parameters of the business environment in one direction, with appropriate changes in the other direction? Does the current strategy of the company contain a strong dependence on one variable of the business environment (where change entails a sharp deterioration in all parameters of the company's activity)? Which new opportunities were identified in the process of analysing the company's strategic risks?

\section{Formation of an effective risk culture of the company}

The practice of risk management and the internal control of the world's leading companies is based on an understanding of determining influences of the general nature of corporate culture on risk culture, and dependence of the latter on the organisational behaviour of employees. The need for the relationship between the principles of employee performance assessment and their motivation with their attention to risk is also a valuable consideration [9]. The set of risk culture development tools is rapidly expanding (internal portal, discussion forum, database on occurred risks, certification, dissemination of information on realised risks, risk culture research, and regular assessment of 
the effectiveness of the tools used, etc.). In analysing these issues and best practices, board members and management can jointly develop answers to the following questions: What are the results of the company's corporate culture assessment in terms of promoting initiative, self-reliance and taking responsibility for their actions? How does management evaluate the organisational behavior of employees in terms of promoting risk culture development? Does the employee performance assessment system sufficiently promote the development of the company's risk culture? Does the employee motivation system sufficiently contribute to the development of their risk culture? How effective are the tools used to develop a risk culture?

\section{Risks of information technology use}

The development of modern information and communication technologies creates new unprecedented opportunities for the integration of various production and service processes, interactions with consumers, and the fostering of innovation. IT and the internet themselves became the basis for radical changes in a huge variety of production and financial processes, as well as the creation of completely new products and markets. At the same time, the cost of possible losses associated with troubles in the operation of information and communication systems, and the loss of knowledge accumulated in them as a result of technical failures is also growing rapidly. In discussing these issues and studying the best practices of other companies in this field, members of the board and management can jointly develop answers to the following questions: What are the weak points identified in the IT security system, and what is the plan to remedy them? What is the cost effectiveness of IT security? How is IT security policy integrated into the company's risk culture development policies, performance assessment system and employee motivation? To what extent is the management familiar with the best practices in ensuring IT security in other companies, and which of their valuable points are used in our company?

The above list of issues on which the board of directors can focus its attention in the process of implementing the function of professional development of management and questions and the answers to which it can formulate in the process of dialogue with management is indicative. Each board should define the list of such issues, their priority, the number and focus of questions specifying their discussion, independently taking into account the specifics of the company activities, the experience of its management and the board members themselves.

\section{Effective practices and tools of the board of directors for professional management development}

Success of implementation by the board of directors of the function of professional management development depends not only on the range of professional areas and issues chosen by the board for this, and on how this choice takes into account the specifics of the company activities. The effectiveness of such work depends to a large extent on practices and tools used by the board for this purpose. Such practices and tools should take into account the psychological barriers which make it difficult for managers to perceive new approaches and ideas, and stimulate a quicker and more complete mastering of these concepts.

Here we will look at some of the most important, practices and tools that board members can use as part of their efforts to provide professional management development. Purposeful discussion by board members and management of the issues of mental distortions and psychological traps in the process of making management decisions, and ways to overcome them. Examples of such distortions and traps can be group thinking, the "mid effect" (exclusion of decisions far from the "golden mean"), "anchoring" (tying reasoning to the figures and facts presented first), "priming" (giving rise to associations that are similar to what a person has faced), and showing stronger negative emotions in a situation arising as a result of ones own actions than in the same situation as a result of inaction.

The professional development of top executives and controlling shareholders by the boards will be more effective if it is done with new practices, techniques and tools. In the author's view, the following ones should be used by boards of Russian companies:

- Regular presentations of experts, the use of coaches, and the identification of these traps in the process of discussing specific management problems can facilitate the maintenance of the reflection of board members and management regarding these issues.

- Purposeful expansion of the framework for joint discussion by board members and management of the most important issues of the company (strategy, business model, market positioning, innovations, risks, etc.). The purpose of this approach is to see the objectives set by the company and the methods of their solutions, on which it relies, in a broad, meaningful context. Such expansion can be carried out in several directions. First, by involving data in the analysis from the industry in which the company operates, but also data from related or even remote industries, but where similar business models are applied. Second, through the incorporation in the analysis of not only Russian, but also international experience. Third, through the extension of timeframes, allowing to see development trends in more distant time horizons (for example, the last three or five years).

- $\quad$ Practice of prepared, purposeful discussions of alternative and even oppositional approaches as a way of countering firm views and approaches in discussing the most important issues of the company.

- Maximum visualsation of the problems discussed and informational materials provided for discussion.

- Benchmarking, compulsory comparability and compatibility (with leaders, competitors) of data when discussing the main activities of the company, and ways to solve the most important problems, and the results obtained. 
- Introduction of the rule of mandatory advance submission by the members of the board and its committees of their written opinions on the agenda. First, it encourages board members to take a more responsible approach to the analysis of materials and the formulation of their questions. Second, it resolves or mitigates the problem of dominance in discussing certain issues of authoritative board members. Third, it gives management time to prepare answers to the questions from members of the board. Fourth, it facilitates an assessment of the quality of work for each board member.

- High-quality preparation of written materials for meetings of the board of directors and its committees. This implies the availability of materials on each important issue, containing a large amount of explanatory materials, and a high-quality summary of the problem and arguments in favour of the proposed method for solving it (summary) of no more than 1.5 pages. A clear division of material into the base one (which is the most important to study), and supplementary materials (reference material, contained in applications). One should seek to minimise text and maximise the use of graphic and tabular materials. The organiser should also limit the total amount of materials sent to members of the board, seeking wherever possible to promptly dispense additional materials upon personal request.

- Mandatory use by board members of previously prepared control questions for management, analysis and subsequent use of the answers received in the course of work (not only at this meeting). Questions should be primarily focused not on quantitative indicators, but on the quality of understanding by the management of the company's managerial processes in the context of management practice development in leading companies in their industry and in other industries, in Russia and internationally. For example, the questions of the company's competitiveness in the industry with regard to its main competitors should be considered, as well as questions such as the quality of business processes, the efficiency of the business model used by the company and the prospects for its change, understanding the sources of innovation and ways to turn them into economic value for the company, effective practices and technologies for the formation of human capital, etc. It will be useful for board members to keep a table in which the essence of the received answers to the asked control questions, their own conclusions, and the appropriateness of obtaining additional information on them from the management are reflected.

\section{Conclusions}

A focus by boards of directors on the development of professional management practices, with a specific emphasis on uncommon approaches to understanding and solving problems will help not only to solve the critical management problem of Russian companies, but also to create acute motivating influences among controlling shareholders to strengthen the actual role of boards of directors in governing companies. This specific focus can help mitigate the conflicts between the functions of boards arising from their nominal legal rights and the framework established by actual ownership relationship in Russian companies.

Board members need to move from focusing on the standard recommendations of international best practice of the boards (within the framework of the control and supervision function), to an in-depth study of key business processes for companies, as well as management innovations, effective international business practices, technologies and tools for promoting new management approaches, and ideas which facilitate the process of overcoming the mental and psychological barriers that impede their effective implementation by the management.

\section{References}

1) Bonnier K.-A., Bruner R.F. An analysis of stock price reaction to management change in distressed firms. Journal of Accounting and Economics. 1989;11(1):95106. DOI: 10.1016/0165-4101(89)90015-3

2) Brett J.F., Cron W.L., Slocum J.W. Economic dependency on work: A moderator of the relationship between organizational commitment and performance. Academy of Management Journal. 1995;38(1):261-271. DOI: 10.5465/256735

3) Nazarova V., Kolykhalina A. The impact of applying internal corporate governance mechanisms on the value of companies using diversification and focusing strategies. Corporate Finance. 2018;12(3):7-26. DOI: 10.17323/j.jcfr.2073-0438.12.3.2018.7-26

4) Ambardnishvili T., Berezinets I., Iliina Yu., Smirnov, M. Board of Directors and dividend policy in Russian companies with direct state participation. Corporate Finance. 2017;11(1):50-77. DOI: 10.17323/j.jcfr.20730438.11.1.2017.50-77

5) 5. Amran N., Yosuf A., Ishak R., Aripin N. Do characteristics of CEO and chairman influence government-linked companies performance? Procedia - Social and Behavioral Sciences. 2014;109:799-803. DOI: 10.1016/j.sbspro.2013.12.546

6) 6. Coughlan A.T., Schmidt R.M. Executive compensation, management turnover, and firm performance: An empirical investigation. Journal of Accounting and Economics. 1985;7(1-3):43-66. DOI: 10.1016/0165-4101(85)90027-8

7) 7. Haleblian J., Finkelstein S. Top management team size, CEO dominance, and firm performance: The moderating roles of environmental turbulence and discretion. The Academy of Management Journal. 1993;36(4):844-863. DOI: $10.2307 / 256761$ 
8) 8. Furtado E.P., Rozeff M.S. The wealth effects of company initiated management changes. Journal of Financial Economics. 1987;18(1):147-160. DOI: 10.1016/0304-405X(87)90065-1

9) Brockmann E.N., Simmonds O.G. Strategic decision making: The influence of CEO experience and use of tacit knowledge. Journal of Managerial Issues. 1997;9(4):454-467.

10) Manne H.G. Mergers and the market for corporate control. Journal of Political Economy. 1965;73(2):110120. DOI: $10.1086 / 259000$

11) Cherepanov A.A., Privalov S.O. Training of top managers is a necessary condition for the efficient quality management. Nauka - promyshlennosti $i$ servisu. 2012;(7):796-798.
12) Sustainable leadership: Talent requirements for sustainable enterprises. Russell Reynolds Associates. 2016. URL: https://www.russellreynolds.com/ insights/thought-leadership/sustainable-leadershiptalent-requirements-for-sustainable-enterprises

13) Elsaid E., Wang X., Davidson W.N. Does experience matter? CEO successions by former CEOs. Managerial Finance. 2011;37(10):915-939. DOI: 10.1108/03074351111161583

14) Brookman J., Thistle P. CEO tenure, the risk of termination and firm value. Journal of Corporate Finance. 2009;15(3):331-344. DOI: 10.1016/j. jcorpfin.2009.01.002 